\title{
Analisis Stabilitas dan Deformasi Terowongan Kereta Cepat Indonesia dengan Pendekatan Numerik Tiga Dimensi
}

\author{
RINALDI ALAMSYAH, INDRA NOER HAMDHAN
}

\author{
Program Studi Teknik Sipil, Institut Teknologi Nasional Bandung \\ Email: alamsyahrinaldi@gmail.com
}

\begin{abstract}
ABSTRAK
Wilayah perkotaan yang didalamnya terdapat perkantoran serta tempat dengan tingkat kegiatan yang sangat tinggi, menjadikan struktur terowongan dibawah tanah solusi yang cocok untuk meningkatkan jenis transportasi massal secara optimal. Terowongan no.1 kereta cepat Indonesia merupakan salah satu terowongan yang dibangun dan berlokasi di Halim, DKI Jakarta. Terowongan dengan panjang 1.885 m ini memiliki jalur ganda (Double Track Railway). Untuk mengetahui stabilitas galian dan deformasi terowongan akibat galian pada saat konstuksi, perlu dilakukan analisis geoteknik. Analisis yang dilakukan yaitu analisis statik dan kondisi longterm dengan analisis dinamik. Metode galian dengan alat Tunneling Bore Machine (TBM) yang menggunakan sistem perkuatan lining precast dan grouting dipilih sebagai metode konstruksi untuk membangun terowongan no. 1. Pemodelan analisis statik menghasilkan deformasi maksimum $0.03056 \mathrm{~m}$ dan nilai faktor keamanan 1.869.
\end{abstract}

Kata kunci: terowongan kereta cepat Indonesia, stabilitas muka galian, deformasi, faktor keamanan, TBM, PLAXIS 3D, lining, grouting

\begin{abstract}
Urban areas with offices and places that have a very high level of activity make underground tunnel structures one of the best solutions to improve public transportation optimally. The Indonesia high speed railway no.1 tunnel is one of the tunnels built and located at Halim, DKI Jakarta. The tunnel with a length of 1,885 $\mathrm{m}$ has a double track (Double Track Railway). To determine the face stability and deformation of the tunnel during construction, it is necessary to conduct geotechnical analysis. The analysis performed is static analysis and longterm conditions with dynamic analysis. Tunneling Bore Machine (TBM) with precast lining reinforcement and grouting system was chosen as the construction method for excavation tunnel no.1. Static analysis modeling produces the maximum deformation $0.03056 \mathrm{~m}$ and a safety factor value of 1.869 .
\end{abstract}

Keywords: tunnel, face stability, deformation, safety factor, TBM, numerical method, PLAXIS 3D, lining, grouting 


\section{PENDAHULUAN}

Upaya mendukung peningkatan jenis trasnportasi massal dengan satu solusi yang optimal adalah dengan membuat terowongan bawah tanah. Terowongan bawah tanah dirancang karena tidak menggunakan area permukaan tanah dalam pembangunannya sehingga merupakan pilihan yang efisien dalam kondisi area yang padat penduduk. Dalam melakukan pembangunan terowongan diperlukan pengalaman serta pemahaman ilmu tentang pengaruh struktur terhadap kondisi tanah, sifat-sifat tanah dan masalah apa saja yang dapat timbul pada saat konstruksi dilaksanakan. Pemahaman ini dimaksudkan untuk pencegahan kegagalan konstruksi dalam pembangunan terowongan tersebut. Menurut Raharjo, P. P. (2004) bahwa terowongan transportasi bawah kota merupakan grup tersendiri diantara terowongan lalu lintas, dapat berupa terowongan kereta api maupun terowongan jalan raya. Faktor terpenting dalam menentukan jenis, bentuk dan biaya untuk terowongan, yaitu dibutuhkan data kondisi batuan atau tanah disekitar terowongan yang lengkap. Terowongan dibuat melalui berbagai jenis lapisan tanah dan bebatuan sehingga metode konstruksi pembuatan terowongan tergantung dari keadaan tanah. Penelitian ini menganalisis deformasi, stabilitas muka (face stability), faktor keamanan dan pengaruh gaya-gaya yang bekerja pada terowongan kereta cepat Indonesia dengan menerapkan beberapa kondisi yang berbeda dengan pendekatan numerik tiga dimensi yang menggunakan software PLAXIS 3D.

\section{KAJIAN PUSTAKA}

\subsection{Definisi Terowongan}

Terowongan adalah suatu jenis struktur yang berada di bawah tanah dengan memiliki dimensi panjang lebih besar daripada lebar penampang galiannya, dan memiliki kemiringan memanjang yang lebih kecil dari $15 \%$. Pada umumnya, terowongan merupakan struktur tertutup pada seluruh bagian sisinya terkecuali pada bagian kedua ujungnya. Beberapa dari ahli teknik sipil dengan bidang keahlian geoteknik mendefinisikan terowongan merupakan suatu struktur tembusan yang berada di bawah tanah dan memiliki panjang minimum 0,1 mil (160,9 meter), apabila panjang kurang dari 160,9 meter maka dapat disebut underpass (Rahardjo, P. P., 2004).

\subsection{Metode Konstruksi Tunnel Boring Machine (TBM)}

Alat penggali terowongan yang memiliki bentuk mesin berupa silinder adalah Tunnel Boring Machine (TBM). Metode konstruksi yang menggunakan alat ini menghasilkan penampang terowongan berbentuk lingkaran. Bagian-bagian yang terdapat pada alat Tunnel Boring Machine (TBM) ini memiliki fungsinya masing-masing. TBM yang terdiri dari komponen alat penggali, alat pemotong, sistem pengoperasian, pengebor, gripper, sistem pengontrol, alat sistem pemasang lining, conveyor, sistem ventilasi udara, penyokong tanah serta sumber tenaga yang dirancang dapat mencapai panjang hingga $300 \mathrm{~m}$. Salah satu contoh dari alat TBM disajikan pada Gambar 1. Batuan keras ( hard rock) maupun tanah lunak (soft soi) dapat ditembus oleh alat pengeboran TBM, hal tersebut merupakan keistimewaan metode konstruksi TBM.

\subsection{Soft Ground Tunnel with Earth Pressure Balance (EPB) Shield Machine}

Pada tanah lunak yang berada di bawah ground water level, mesin bor dengan jenis ini dapat digunakan tanpa slurry mixture. Cara kerja mesin ini yaitu dengan menyeimbangkan tekanan tanah (earth pressure) dan air tanah pada muka galian dengan tekanan pada excavation chamber pada mesin TBM. Pengaturan kecepatan penggalian mesin TBM dan screw conveyor dilakukan untuk mengendalikan tekanan pada excavation chamberdalam memindahkan tanah hasil galian dalam excavation chamber keluar 


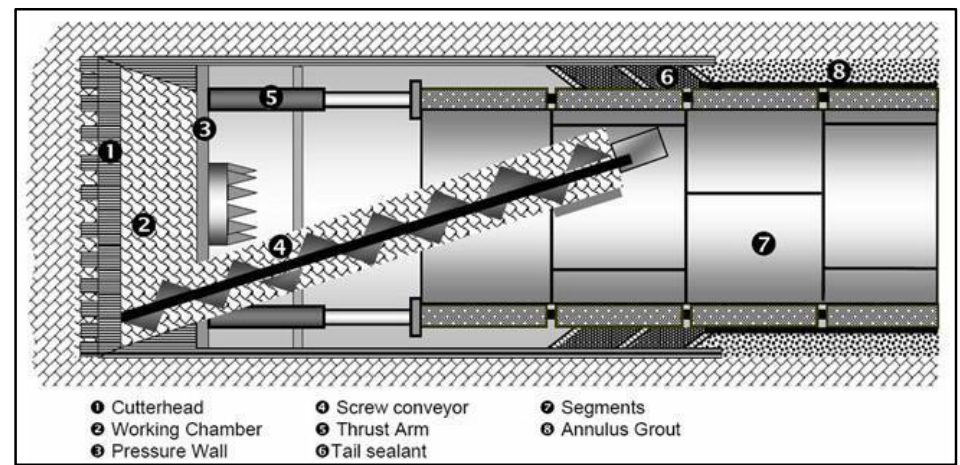

Gambar 1. TBM dengan tipe earth pressure balance

(Sumber: Center for Underground Infrastructure Research and Education, 2016)

\subsection{Metode Numerik (PLAXIS 3D)}

Perangkat lunak PLAXIS 3D merupakan salah satu metode numerik berbasis pemograman perangkat lunak yang cukup sederhana dan sering digunakan untuk bidang geoteknik. Pada dasarnya, PLAXIS 3D menggunakan penyelesaian metode elemen hingga (FEM) sehingga didapatkan sebuah persamaan berdasarkan masalah yang dianalisis dengan pendekatan pada titik tertentu yang memiliki nilai tidak diketahui pada sistem perhitungan secara berkesambungan. Jika suatu sistem diberikan sebuah gaya dari luar, maka gaya tersebut langsung diserap dan menghasilkan gaya dalam serta perpindahan yang dimana merupakan konsep dasar dari metode elemen hingga. Diperlukan sebuah persamaan yang dapat mewakili sistem tersebut agar kita dapat mengetahui besaran gaya dalam dan perpindahan yang dihasilkan oleh adanya gaya dari luar tersebut. Matriks persamaan dapat didefinisikan seperti disajikan pada Persamaan 1.

$$
[K]\{D\}=\{R\}
$$

halmana:

$[K] \quad=$ matriks gaya global,

$\{D\} \quad=$ matriks perpindahan global,

$\{R\} \quad=$ matriks kekakuan global.

\subsection{Hardening Soil Model}

Hardening Soil Model (HS Mode) dirancang oleh Schanz pada tahun 1999. Hardening Soil merupakan model yang dapat mensimulasikan perilaku suatu jenis tanah, baik tanah kaku maupun tanah lunak, yang berbeda menurut Schanz. Tanah mengalami penurunan kekakuan serta mengalami peningkatan tegangan plastik secara simultan saat mengalami pembebanan deviatorik primer. Berbeda dengan Mohr-Coulomb Model, gabungan tiga parameter stiffness input yaitu triaxial loading stiffness (E50), triaxial unloading-reloading stiffness (Eur) dan oedometer loading modulus (Eoed) dapat menghasilkan nilai deformasi tanah dengan lebih akurat. Seperti yang ditunjukan oleh kurva pada Gambar 3 dengan pengaturan default $P^{r e f}$ $=100 \mathrm{kN} / \mathrm{m}^{2}$, PLAXIS 3D mendefinisikan besaran nilai secant stiffness pada pengujian triaxial drained $\left(E_{50}^{r e f}\right)$ sebesar lima puluh persen dari nilai tegangan deviatorik maksimum. Tegangan terbatas pada uji triaxial $\left(\sigma^{\prime}{ }_{3}\right)$ atau biasa disebut dengan tegangan utama minor, mempengaruhi kekakuan. Pada pengaturan default program PLAXIS 3D mendefinisikan nilai unloading-reloading striffness $\left(E_{u r}^{\text {ref }}\right)=3 E_{50}^{\text {ref }}$. Untuk kompresi satu dimensi, HS-Standard elastoplastik tidak melibatkan hubungan tetap antara kekakuan oedometer $E_{\text {oed }}$ dan kekakuan triaksial (undrained) $E_{50}$. Gambar 4 menunjukan kurva yang digunakan untuk mendefinisikan nilai $E_{\text {oed }}^{\text {ref }}$ atau pembebanan primer oedometer untuk persamaan tangent stiffness. 


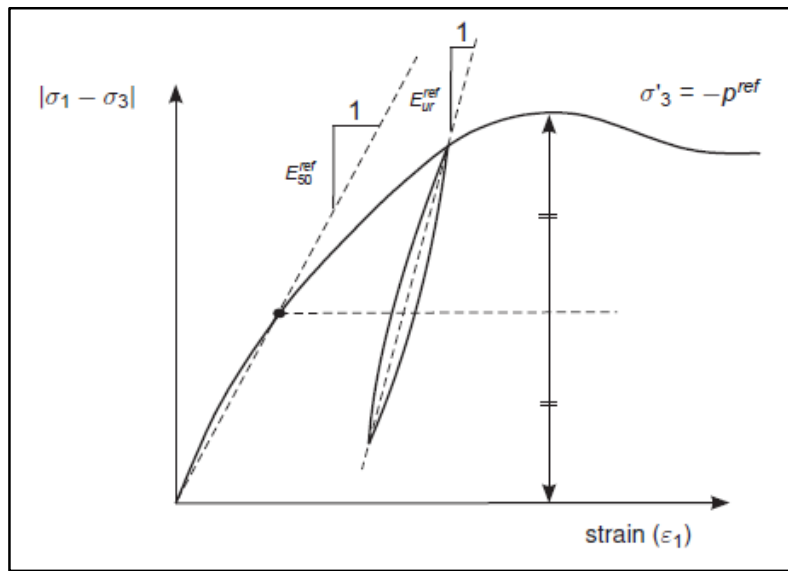

Gambar 2. Definisi nilai $E_{50}^{r e f}$ dan $E_{u r}^{r e f}$ dari hasil uji triaxial drained

(Sumber: Brinkgreeve, R. B. J., 2019)

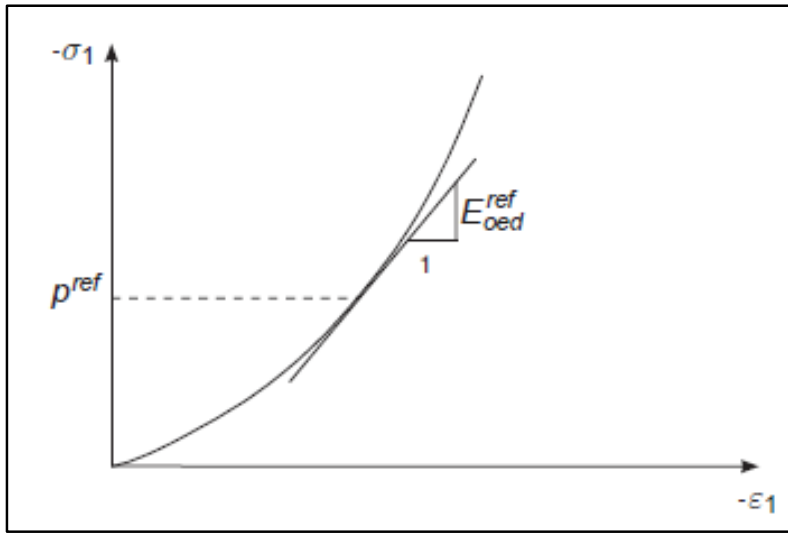

Gambar 3. Definisi nilai $E_{\text {oed }}^{r e f}$ dari hasil pengujian oedometer (Sumber: Brinkgreeve, R. B. J., 2019)

\subsection{Face Support Pressure}

Tanah dengan muka galian yang tidak kohesif, dalam praktik perhitungan face support pressure dapat dengan mudah dilakukan dengan menggunakan metode kesetimbangan batas (LEM). Soil parameter effective shear strength diasumsikan berada dalam kondisi drained untuk perhitungan ini. Jancsecz dan Steiner (1994) mengatakan, langkah awal yang dilakukan untuk melakukan analisis perhitungan face support pressure diwakili oleh definisi mekanisme keruntuhan. Diameter area muka galian terowongan yang berbentuk lingkaran diperkirakan sama dengan muka galian terowongan bentuk persegi untuk panjang tepinya. Maka, pola keruntuhan tanah yang terjadi pada area muka galian terowongan dapat diasumsukan seperti pada Gambar 4. Besaran macam-macam gaya yang bekerja pada bagian atas muka galian terowongan dapat dihitung setelah mengetahui bidang keruntuhan tersebut dan sekaligus besarnya nilai beban-beban yang bekerja diatas permukaan tanah. 


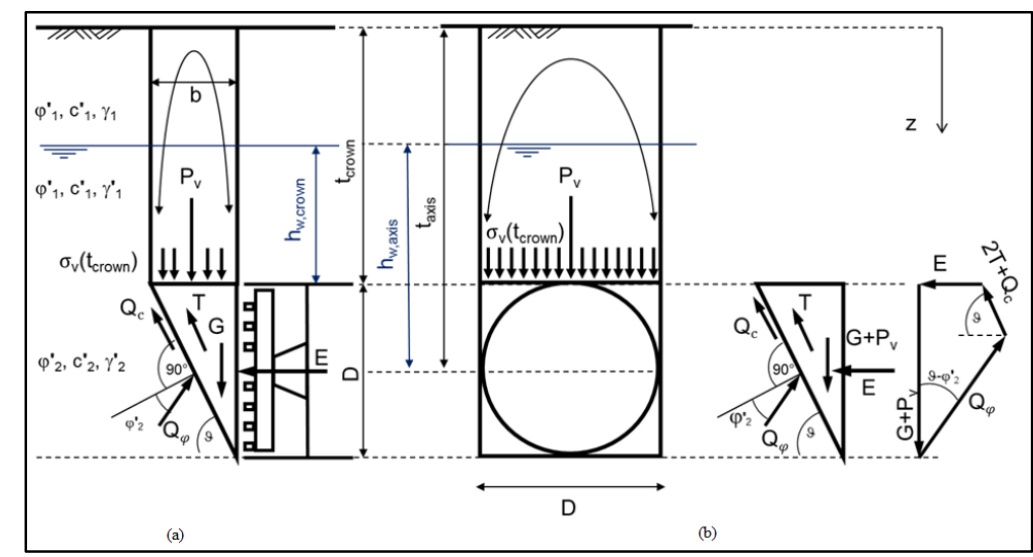

Gambar 4. Mekanisme keruntuhan akibat galian terowongan

(a) arah memanjang \& (b) arah melintang

(Sumber: Zizka, Z. \& Thewes, M., 2016)

Gaya face support pressure dapat dihitung dengan menjumlahkan dua kondisi keseimbangan menggunakan Persamaan 2.

$$
E_{r e}(\vartheta)=\frac{\left(G+P_{V}\right) \cdot\left(\sin (\vartheta)-\cos (\vartheta) \cdot \tan \left(\varphi_{2}^{\prime}\right)\right)-2 \cdot T-c_{\prime} 2 \cdot \frac{D^{2}}{\sin (\vartheta)}}{\sin (\vartheta) \cdot \tan \left(\varphi_{2}^{\prime}\right)+\cos (\vartheta)}
$$

halmana:

$E_{r e} \quad=$ face support pressure penampang galian persegi [kN],

$P_{V} \quad=$ berat pada irisan penampang galian akibat tekanan overburden [kN],

$G \quad=$ berat tanah pada irisan penampang galian $[\mathrm{kN}]$,

$T \quad=$ gaya geser pada permukaan slip vertikal $[\mathrm{kN}]$,

$\vartheta \quad=$ sudut bidang keruntuhan galian [0],

${c^{\prime}}_{2}=$ kohesi tanah $\left[\mathrm{kN} / \mathrm{m}^{2}\right]$,

$D=$ diameter terowongan $[\mathrm{kN}]$,

$\varphi_{2}^{\prime} \quad=$ sudut geser tanah [0].

\section{METODOLOGI PENELITIAN}

\subsection{Bagan Alir Penelitian}

Metode penelitian yang akan dilakukan dijabarkan melalui bagan alir penelitian. Adapun bagan alir penelitian penelitian ini disajikan pada Gambar 5.

\subsection{Pengumpulan Data}

Data-data yang digunakan pada penelitian ini meliputi data struktur terowongan, data parameter tanah, data topografi, dan data gempa.

\subsubsection{Data Struktur Terowongan}

Data struktur terowongan diperlukan untuk membuat geometri model terowongan. Bentuk penampang terowongan dapat dilihat pada Gambar 6. Data-data yang digunakan diantaranya sebagai berikut:

1. Diameter terowongan.

2. Tebal lining precast.

3. Panjang grouting.

4. Diameter grouting.

5. Berat jenis beton. 
6. Kuat tekan beton lining.

7. Kuat tekan beton grouting.

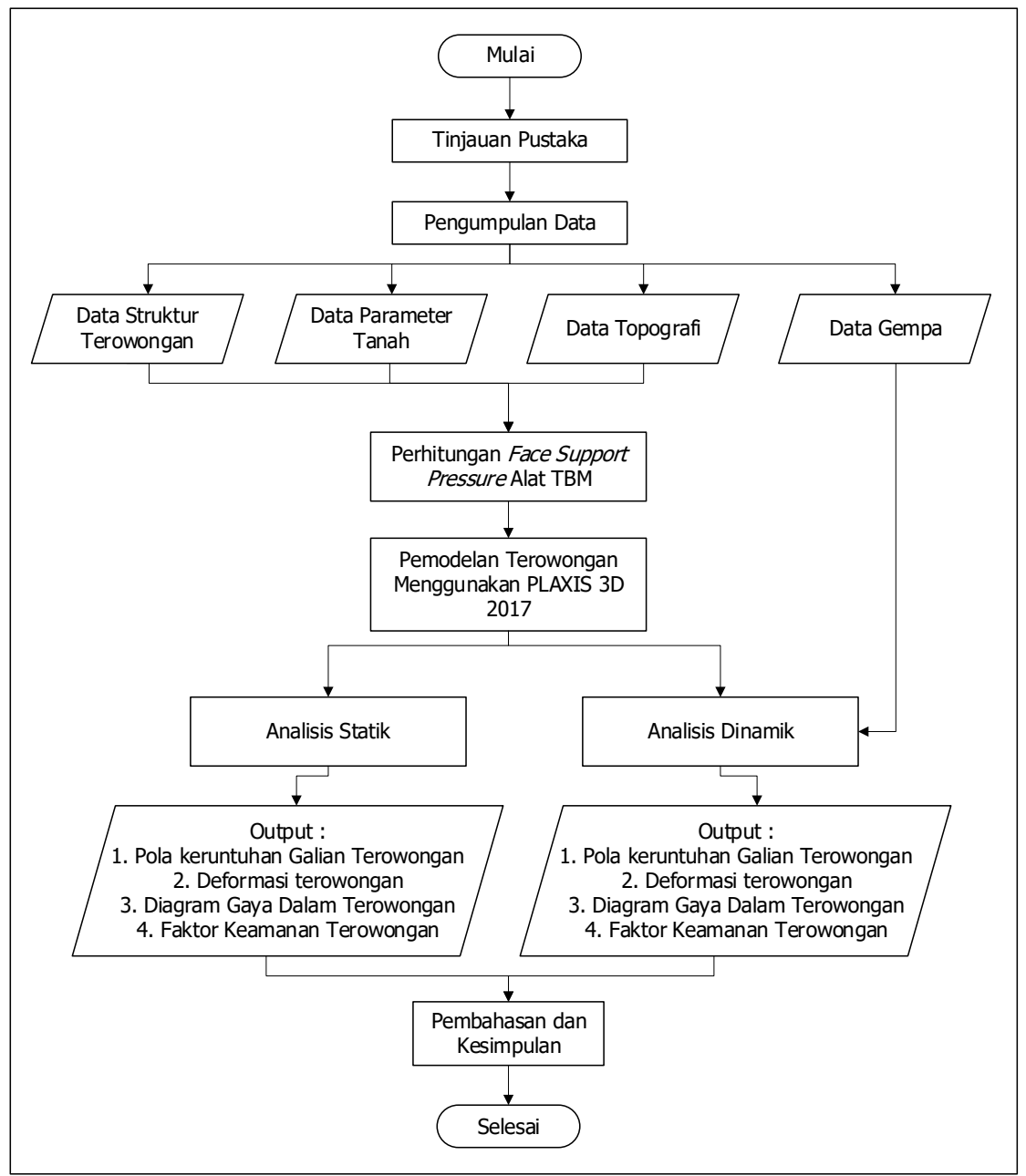

Gambar 5. Bagan alir penelitian

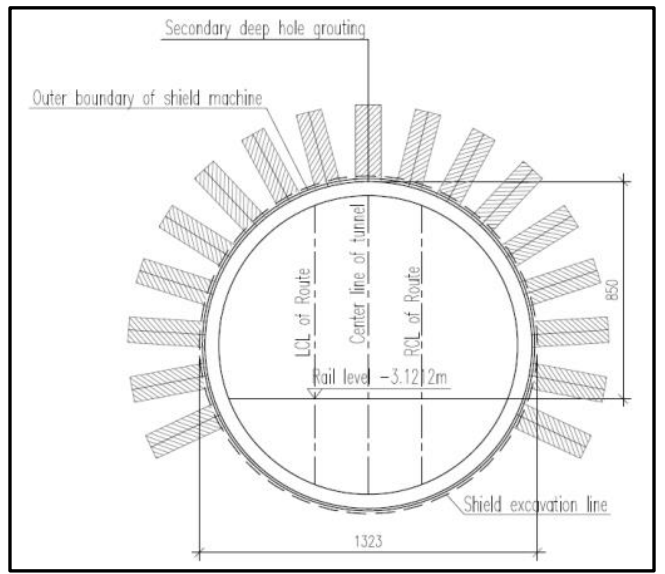

Gambar 6. Data bentuk penampang terowongan

\subsubsection{Data Parameter Tanah}

Data parameter tanah yang digunakan pada pemodelan adalah seperti yang disajikan pada Tabel 1. Soil model yang digunakan pada pemodelan adalah hardening soil model. 
Tabel 1. Parameter Tanah yang Digunakan

\begin{tabular}{ccccccccc}
\hline $\begin{array}{c}\text { Tebal } \\
\text { Lapisan } \\
{[\mathbf{m}]}\end{array}$ & $\boldsymbol{N} \boldsymbol{S P T}$ & $\begin{array}{c}\text { Jenis } \\
\text { Tanah }\end{array}$ & $\begin{array}{c}\boldsymbol{\gamma}_{\text {unsat }} \\
{\left[\mathbf{k N} / \mathbf{m}^{3}\right]}\end{array}$ & $\begin{array}{c}\boldsymbol{\gamma}_{\text {sat }} \\
{\left[\mathbf{k N} / \mathbf{m}^{3}\right]}\end{array}$ & $\begin{array}{c}\boldsymbol{E}^{\prime} \\
{[\mathbf{k P a}]}\end{array}$ & $\begin{array}{c}\boldsymbol{\varphi}^{\prime} \\
{\left[{ }^{\circ}\right]}\end{array}$ & $\begin{array}{c}\mathbf{c}^{\prime} \\
{[\mathbf{k P a}]}\end{array}$ & $\begin{array}{c}\boldsymbol{k} \\
{[\mathbf{m} / \mathbf{d a y}]}\end{array}$ \\
\hline 5,5 & 4 & clay & 14 & 15 & 6.000 & 29 & 16 & 0,000864 \\
\hline 11,5 & 8 & clay & 15 & 16 & 12.000 & 31 & 20 & 0,000864 \\
\hline 9,7 & 48 & clay & 17 & 18 & 72.000 & 25 & 46 & 0,000864 \\
\hline 2 & 50 & sand & 20 & 21 & 38.300 & 48 & 9 & 8,64 \\
\hline 1,2 & 50 & clay & 17 & 18 & 75.000 & 27 & 43 & 0,00864 \\
\hline 5,3 & 49 & sand & 20 & 21 & 37.534 & 47 & 7 & 8,64 \\
\hline 15,75 & 30 & clay & 16 & 17 & 45.000 & 42 & 50 & 0,000864 \\
\hline 2 & 48 & silt & 19 & 20 & 72.000 & 28 & 45 & 0,0864 \\
\hline 1 & 50 & sand & 18 & 19 & 38.300 & 48 & 20 & 0,864 \\
\hline 0,7 & 32 & sand & 18 & 19 & 24.512 & 42 & 17 & 0,864 \\
\hline 1,5 & 33 & clay & 17 & 18 & 49.500 & 43 & 50 & 0,00864 \\
\hline
\end{tabular}

\subsubsection{Data Topografi}

Data topografi yang digunakan merupakan salah satu data stratigrafi tanah dari sepanjang trase terowongan seperti pada Gambar 7.

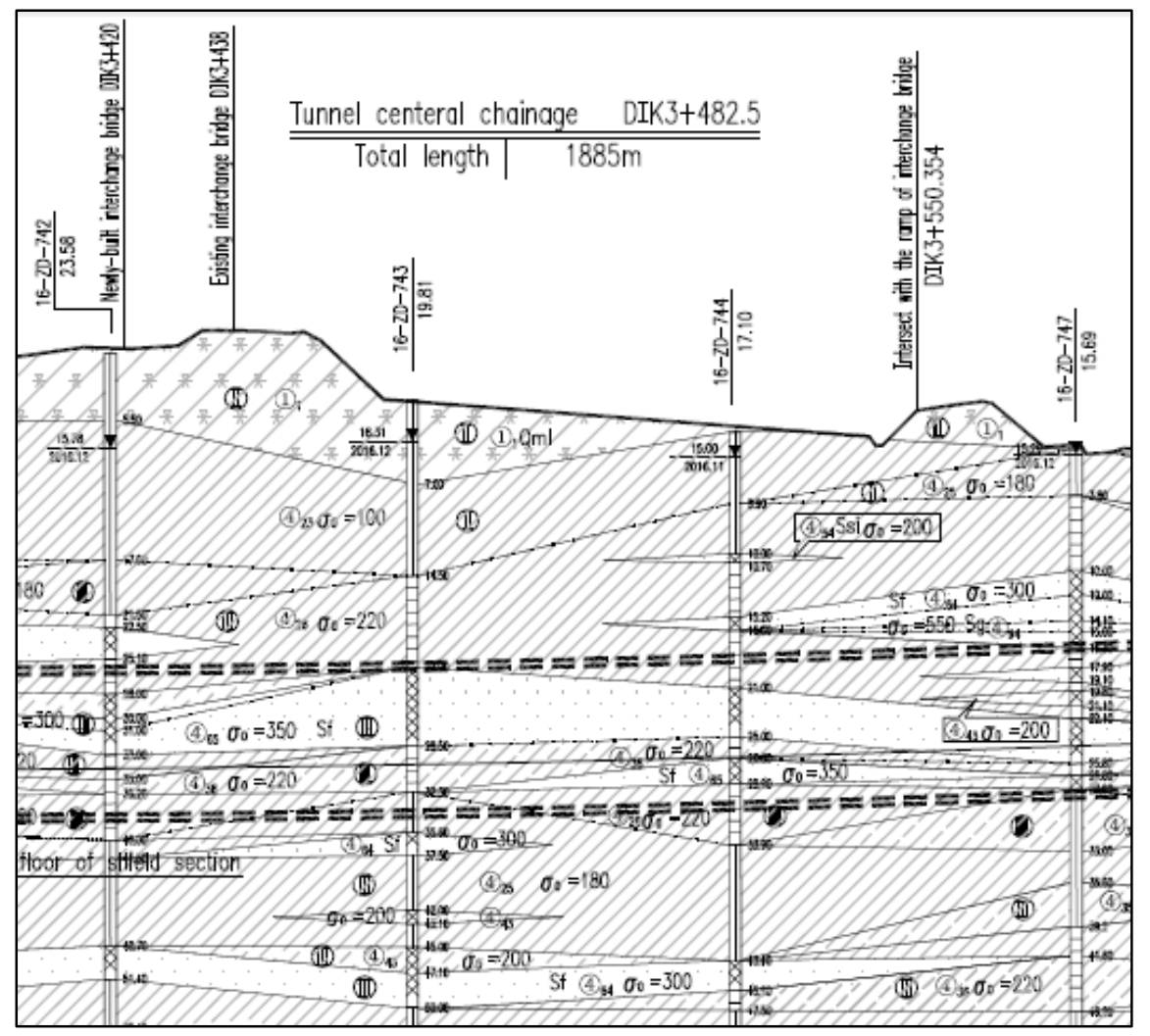

Gambar 7. Data stratigrafi tanah yang digunakan

\subsubsection{Perhitungan Face Support Pressure}

Perhitungan face support pressure diperlukan karena dalam pemodelan galian dengan metode konstruksi menggunakan alat TBM pada program PLAXIS 3D tidak ada pengaturan otomatis gaya tekan ke arah muka galian yang disebabkan oleh alat TBM. Sehingga perlu dilakukan pendekatan dengan mensimulasikan gaya tekan yang terjadi ke arah muka galian dengan 
menggunakan beban merata seluas diameter galian yang dimodelkan. Hasil dari perhitungan dengan menggunakan metode limit equilibrium method (LEM) ditunjukkan pada Tabel $\mathbf{2}$ dan Gambar 8.

Tabel 2. Hasil Perhitungan Kesetimbangan Batas

\begin{tabular}{ccccccccccc}
\hline $\boldsymbol{\vartheta}$ & $\begin{array}{c}\boldsymbol{t a n} \\
(\boldsymbol{\vartheta})\end{array}$ & $\begin{array}{c}\boldsymbol{s i n} \\
(\boldsymbol{\vartheta})\end{array}$ & $\begin{array}{c}\boldsymbol{c o s} \\
(\boldsymbol{\vartheta})\end{array}$ & $\boldsymbol{G}$ & $\boldsymbol{P}_{\boldsymbol{V}}$ & $\boldsymbol{K}_{\mathbf{2}}$ & $\boldsymbol{T}_{\boldsymbol{R}}$ & $\boldsymbol{T}_{\boldsymbol{C}}$ & $\boldsymbol{T}$ & $\boldsymbol{E}_{\boldsymbol{r e}}$ \\
\hline 55 & 1,43 & 0,82 & 0,57 & $6.607,99$ & $25.823,92$ & 0,403 & $3.655,69$ & $2.179,72$ & $5.835,41$ & $-3.642,35$ \\
\hline 65 & 2,14 & 0,91 & 0,42 & $4.400,63$ & $17.197,61$ & 0,403 & $2.434,53$ & $1.451,60$ & $3.886,13$ & $-570,41$ \\
\hline 69 & 2,61 & 0,93 & 0,36 & $3.622,60$ & $14.157,05$ & 0,403 & $2.004,10$ & $1.194,95$ & $3.199,06$ & $-322,77$ \\
\hline 85 & 11,43 & 1,00 & 0,09 & 825,65 & $3.226,62$ & 0,403 & 456,77 & 272,35 & 729,12 & $-5.663,02$ \\
\hline
\end{tabular}

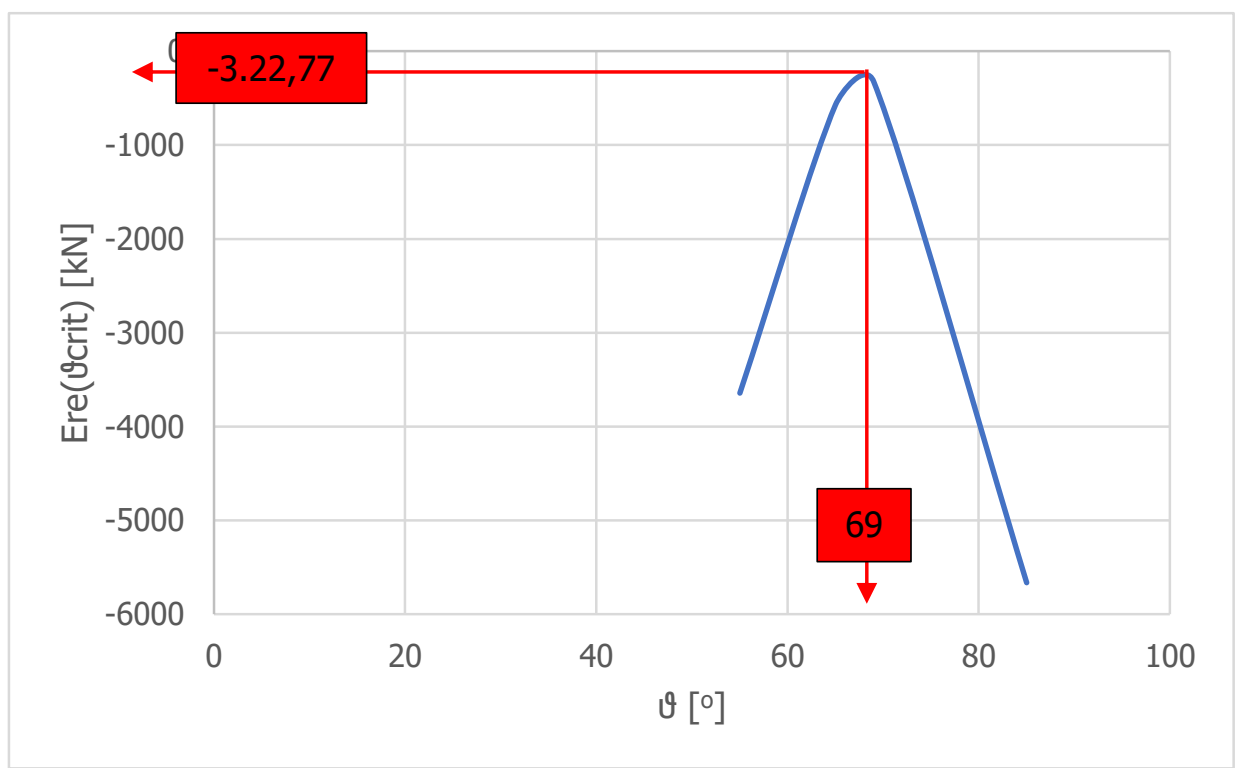

Gambar 8. Kurva Penentuan Nilai $E_{\text {max }, r e}$

Berdasarkan hasil perhitungan yang ditunjukkan Tabel $\mathbf{2}$ dan Gambar $\mathbf{8}$ nilai $E_{\max , r e}$ yang diperoleh adalah negatif sehingga untuk perhitungan selanjutnya digunakan nilai $E_{\text {max,re }}$ sebesar $0 \mathrm{kN}$. Hasil akhir dalam menentukan nilai face support pressure berdasarkan perhitungan kesetimbangan batas dapat dilihat pada Tabel $\mathbf{3}$.

Tabel 3. Hasil Akhir Perhitungan Face Support Pressure

\begin{tabular}{ccccc}
\hline $\begin{array}{c}\boldsymbol{E}_{\max , c i} \\
{[\mathbf{k N}]}\end{array}$ & $W_{r e}[\mathbf{k N}]$ & $W_{c i}[\mathbf{k N}]$ & $\begin{array}{c}\boldsymbol{S}_{c i} \\
{[\mathbf{k N}]}\end{array}$ & $\begin{array}{c}\boldsymbol{S}_{\boldsymbol{c} \text { (i }} \\
{\left[\mathbf{k N} / \mathbf{m}^{2}\right]}\end{array}$ \\
\hline 0 & $40.468,48$ & $31.796,66$ & $33.386,50$ & 259,35 \\
\hline
\end{tabular}

\subsubsection{Data Gempa}

Data gempa yang digunakan menggunakan data dari peta Pusat Studi Gempa Nasional tahun 2017 dengan probabilitas terlampaui 7\% dalam 75 tahun. Peta percepatan gempa dapat dilihat pada Gambar 9. 


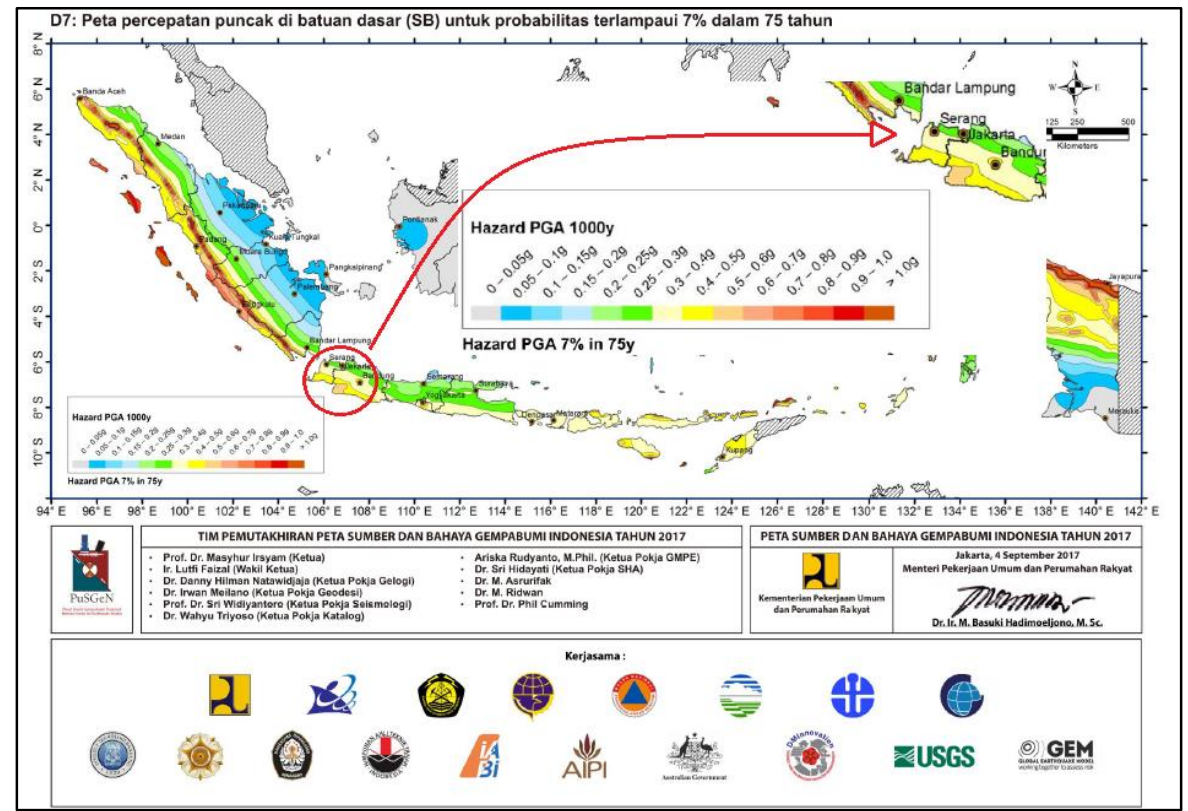

Gambar 9. Data peta gempa

(Sumber: Pusat Studi Gempa Nasional, 2017)

\subsection{Pembuatan Model}

Pembuatan model terowongan hanya memodelkan terowongan sepanjang 40 meter, yaitu terowongan pada STA DIK3+420 sampai DIK3+460. Model yang ditunjukkan pada Gambar $\mathbf{1 0}$ adalah model dengan perkuatan lining ditambah perkuatan grouting.

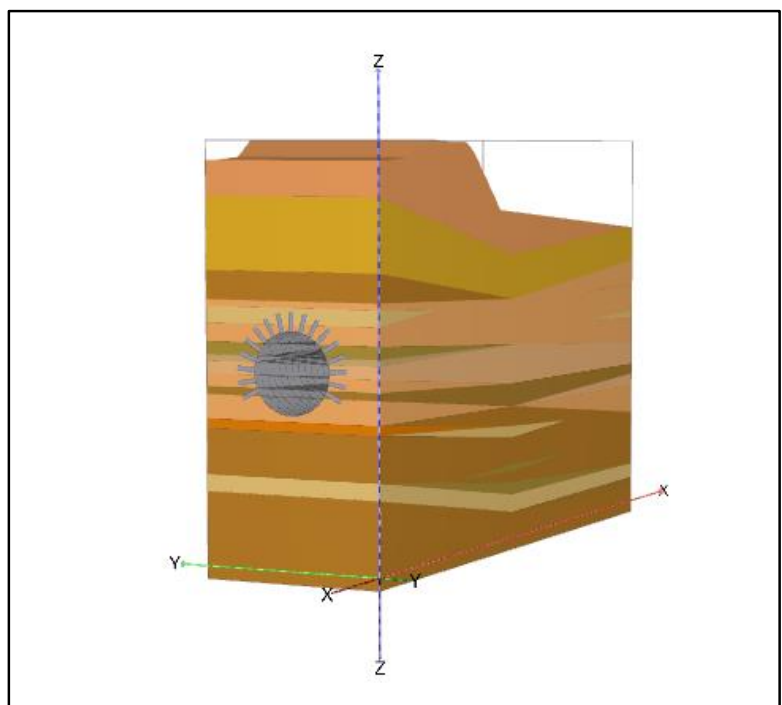

Gambar 10. Model dengan perkuatan lining dan grouting

\section{HASIL PENELITIAN}

Hasil proses analisis statik dan analisis dinamik dari pemodelan terowongan kereta cepat Indonesia yaitu nilai total displacement, shear force, axial force, bending moment, dan safety factor. Hasil dari analisis statik membandingkan antara pemodelan terowongan dengan perkuatan lining ditambah grouting dan pemodelan terowongan dengan perkuatan lining tanpa grouting. Hasil analisis dinamik untuk mengetahui kondisi terowongan terhadap pengaruh gempa pada saat kondisi longterm. Tabel 4 menunjukkan perbandingan nilai deformasi dari 
dua kondisi sistem perkuatan pada setiap panjang galian. Titik kritis dari akibat adanya proses penggalian terowongan dapat dilihat pada Gambar 12 ditunjukkan dengan adanya gradasi warna merah.

Tabel 4. Perbandingan Deformasi dari Dua Kondisi Sistem Perkuatan

\begin{tabular}{ccc}
\hline \multirow{2}{*}{$\begin{array}{c}\text { Kedalaman } \\
{[\mathrm{m}]}\end{array}$} & \multicolumn{2}{c}{$\begin{array}{c}\text { Deformasi } \\
{[\mathrm{m}]}\end{array}$} \\
\cline { 2 - 3 } & Lining & Lining + Grouting \\
\hline 6 & 0,0233 & 0,0233 \\
\hline 12 & 0,02717 & 0,02719 \\
\hline 18 & 0,02902 & 0,02905 \\
\hline 24 & 0,03 & 0,03003 \\
\hline 30 & 0,03046 & 0,03051 \\
\hline 36 & 0,03056 & 0,03057 \\
\hline 40 & 0,02977 & 0,0298 \\
\hline
\end{tabular}

Berdasarkan hasil analisis dari Tabel $\mathbf{4}$ dan Gambar $\mathbf{1 1}$ dengan adanya penambahan grouting tidak berpengaruh secara signifikan. Hal tersebut karena kondisi tanah pada bagian atas terowngan tergolong dalam kondisi stabil atau kaku. Sehingga dengan dilakukan penambahan grouting tidak optimal karena hanya akan menambah nilai deformasi yang disebabkan oleh berat sendiri dari grouting. Selanjutnya hasil dari analisis berupa gaya-gaya dalam yang terjadi pada sistem perkuatan terowongan. Dapat dilihat pada Tabel $\mathbf{5}$ menunjukkan besaran gayagaya dalam yang terjadi setiap panjang galian serta hasil analisis dari faktor keamanan pada setiap panjang galian dapat dilihat pada Tabel 6.

Tabel 5. Gaya-Gaya Dalam yang Terjadi pada Sistem Perkuatan

\begin{tabular}{ccccccc}
\hline \multirow{2}{*}{$\begin{array}{c}\text { Kedalaman } \\
{[\mathbf{m}]}\end{array}$} & $\begin{array}{c}\text { Axial Force } \\
{[\mathbf{k N} / \mathbf{m}]}\end{array}$ & $\begin{array}{c}\text { Shear Force } \\
{[\mathrm{kN} / \mathbf{m}]}\end{array}$ & $\begin{array}{c}\text { Bending Moment } \\
{[\mathrm{kNm} / \mathbf{m}]}\end{array}$ \\
\cline { 2 - 7 } & Min & Maks & Min & Maks & Min & Maks \\
\hline 6 & $-497,7$ & 269,3 & $-293,3$ & 286,7 & $-408,4$ & 106,7 \\
\hline 12 & -1.393 & 935,5 & $-517,3$ & 507,9 & $-491,3$ & 157,6 \\
\hline 18 & -2.083 & 1.560 & $-584,3$ & 573,4 & $-505,9$ & 171,2 \\
\hline 24 & -2.486 & 2.013 & $-566,7$ & 553,1 & $-503,6$ & 172 \\
\hline 30 & -2.693 & 2.389 & $-531,5$ & 520,3 & $-498,9$ & 170,5 \\
\hline 36 & -2.791 & 2.740 & $-509,9$ & 497,8 & $-495,4$ & 170,1 \\
\hline 40 & -3.101 & 2.730 & $-567,4$ & 556,1 & $-492,5$ & 166,3 \\
\hline
\end{tabular}

Tabel 6. Hasil Akhir Perhitungan Face Support Pressure

\begin{tabular}{cc}
\hline Kedalaman [m] & Faktor Keamanan \\
\hline 6 & 1,914 \\
\hline 12 & 1,913 \\
\hline 18 & 1,913 \\
\hline 24 & 1,911 \\
\hline 30 & 1,910 \\
\hline 36 & 1,869 \\
\hline 40 & 1,891 \\
\hline
\end{tabular}




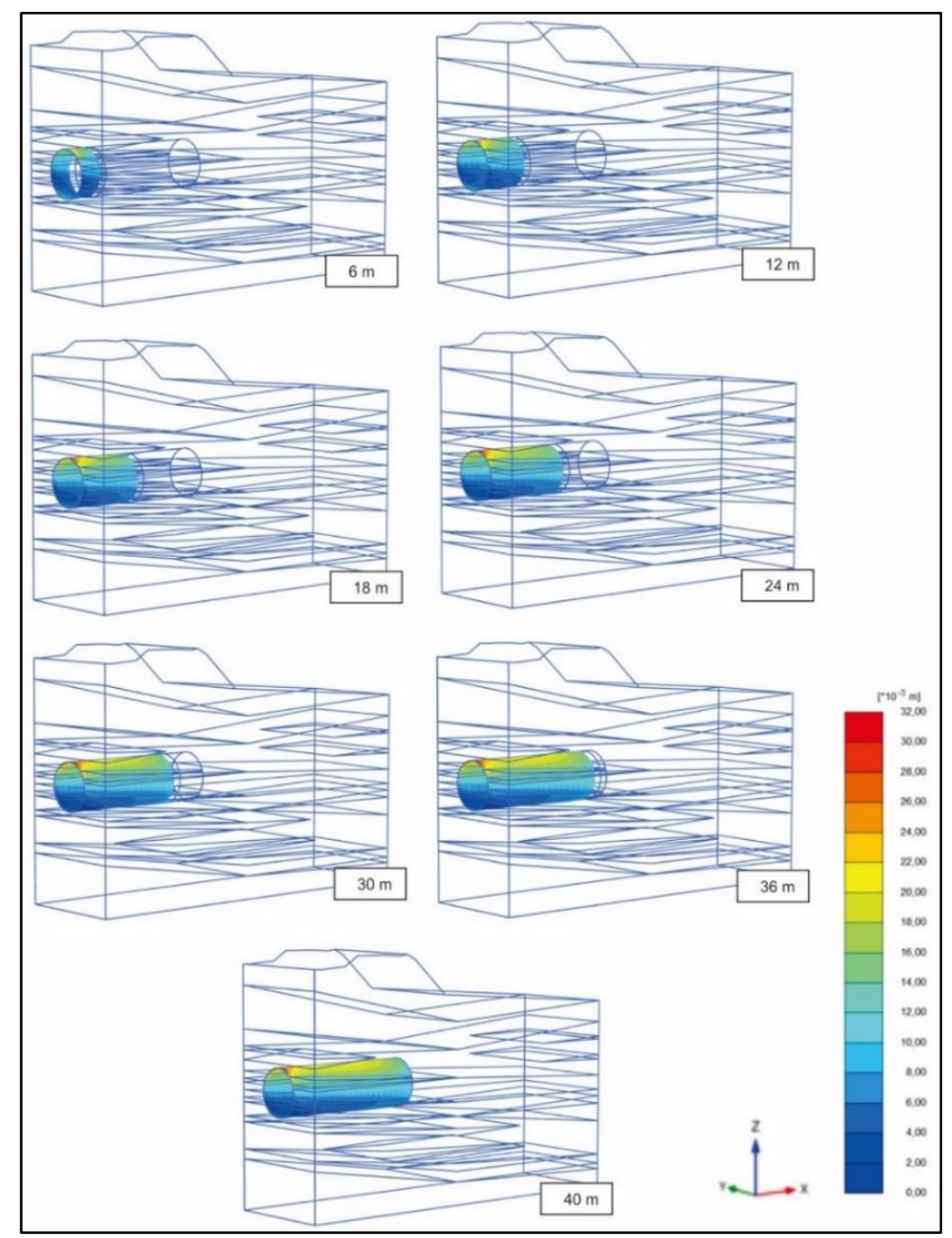

Gambar 11. Total displacement yang terjadi setiap panjang galian

Hasil dari nilai gaya-gaya dalam yang terjadi pada sistem perkuatan terowongan menghasilkan nilai-nilai axial force terbesar $3.101 \mathrm{kN} / \mathrm{m}$; shear force terbesar 584,3 kN/m; dan bending moment 505,9 kNm/m. Hal tersebut dapat digunakan untuk keperluan pengecekan ulang terhadap dimensi sistem perkuatan. Dari nilai positif dan negatif yang dihasilkan pada Tabel 5 menunjukan distribusi arah gaya yang terjadi seperti yang disajikan pada Gambar 12. Untuk hasil analisis dari faktor keamanan yang disajikan pada Tabel 6 menunjukkan nilai faktor keamanan dari titik kritis pada model geometri yang dibuat. Terakhir bidang keruntuhan yag disebabkan adanya penggalian terowongan dapat dilihat pada Gambar 13.

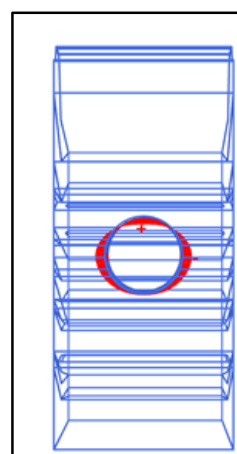

(a)

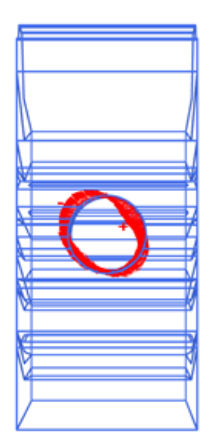

(b)

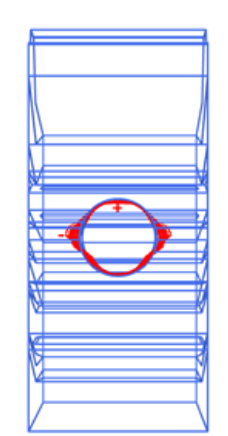

(c)

Gambar 12. Distribusi arah gaya axial force (a), shear force (b), bending moment (c) pada sistem perkuatan

RekaRacana: Jurnal Teknik Sipil - 121 


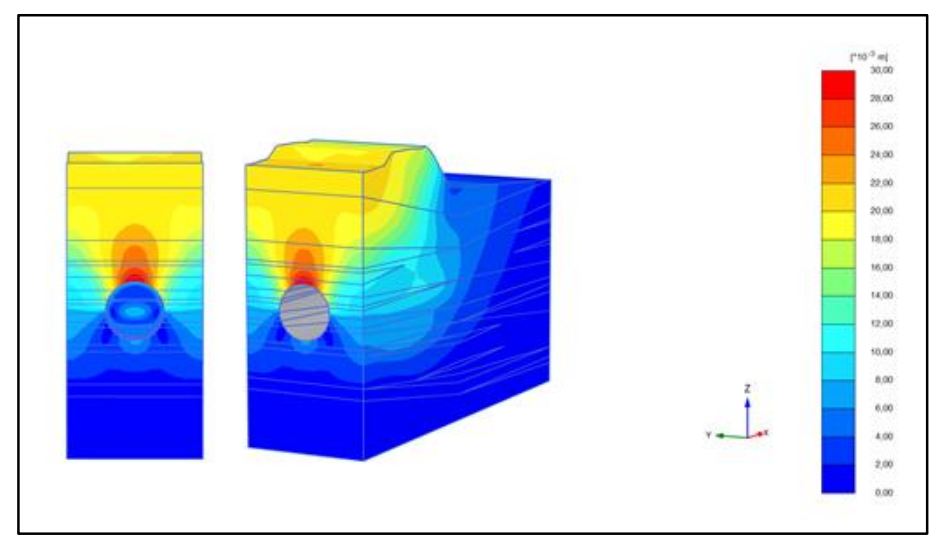

Gambar 13. Pola keruntuhan akibat galian terowongan

\section{KESIMPULAN}

Berdasarkan hasil dari nilai total displacement pada saat pelaksanaan konstruksi yang membandingkan dua model dari sistem perkuatan. Dari hasil tersebut menunjukkan bahwa penambahan perkuatan grouting tidak optimal karena perbandingan nilai deformasinya tidak signifikan dengan nilai deformasi terbesar keduanya 0,0306 m. Kondisi tersebut disebabkan karena stabilitas muka galian atau face stability termasuk dalam kondisi yang stabil.

Besaran dari nilai-nilai gaya dalam yang dihasilkan dari proses analisis dapat digunakan untuk melakukan pengecekan ulang terhadap dimensi sistem perkuatan. Seperti, untuk kebutuhan tulangan lining serta tebal lining pada tahap perencanaan desain terowongan. Dengan menggunakan nilai axial force $3.101 \mathrm{kN} / \mathrm{m}$; shear force $548,3 \mathrm{kN} / \mathrm{m}$; serta nilai bending moment 505,9 kNm/m.

Nilai faktor keamanan yang dihasilkan dari pemodelan merupakan nilai faktor keamanan dari kondisi lereng bukit yang ada diatas terowongan. Hal tersebut karena pada program PLAXIS 3D dalam menganalisis safety factor mencari kondisi paling kritis dari geometri atau model yang dibuat. Dengan demikian, nilai faktor keamanan galian terowongan sudah dipastikan akan lebih besar dari nilai SF 1,869.

\section{DAFTAR RUJUKAN}

Brinkgreve, R. B. (2019). Plaxis Material Model Manual 2019. Delft: Plaxis BV.

Center for Underground Infrastructure Research and Education. (2016). Integrating Underground Freight Transportation into Existing Intermodal Systems. Project No.: 06870. Arlington, Texas: University of Texas.

Jancsecz S., S. W. (1994). Face support for large mix-shield in heterogeneous ground conditions, in Proc Tunnelling '94, pp. 531-550. London: Chapman and Hall.

Pusat Studi Gempa Nasional. (2017). Peta Sumber dan Bahaya Gempa Indonesia Tahun 2017. Bandung: Pusat Litbang Perumahan dan Permukiman - Kementerian PUPR.

Rahardjo, P. P. (2004). Teknik Terowongan. Bandung: Univesitas Katolik Parahyangan.

Schanz, T. V. (1999). The hardening-soil model: Formulation and verification. In R. B.J. 281290. Rotterdam: Beyond 2000 in Computational Geotechnics.

Zizka, Z. \&. (2016). Recommendations for Face Support Pressure Calculations for Shield Tunnelling in Soft Ground. Version 10/2016. Koln: Deutscher Ausschuss für unterirdisches Bauen e. V. (DAUB) \& German Tunnelling Committee (ITA-AITES). 